\title{
MÉTODO DO ESTUDO DE CASO SOBRE AGROTÓXICOS PARA O ENSINO DE QUÍMICA DE JOVENS E ADULTOS (EJA)
}

\author{
Laurine Cristina Paulo da Silva \\ Verônica Joyce Vieira da Silva \\ Thaís Nunes Lopes \\ André Marques dos Santos
}

"Ninguém educa ninguém, ninguém educa a si mesmo, os homens se educam entre si, mediatizados pelo mundo" (FREIRE)

\section{Introdução}

A educação no Brasil teve início no século XVI com uma prática marcada pelos interesses das classes dominantes caracterizada por ser desigual e excludente desde seu início. $\mathrm{O}$ ensino dedicado a jovens e adultos (EJA) ao longo desta história passou por avanços e retrocessos, tendo como documentos norteadores a Constituição Federal de 1988, a Lei de Diretrizes e Bases da Educação de 1996 e as Diretrizes Curriculares específicas de 2000, que delegam ao Poder Público o dever de viabilizar $o$ acesso e permanência gratuito ao ensino com adequa- 
ções às características, necessidades e disponibilidades desse público (BRASIL, 1996).

Assim, essa modalidade de ensino possibilita a volta às salas de aula para jovens e adultos acima de 15 anos (ensino fundamental) e acima dos 18 anos (ensino médio), que não tenham concluído os estudos na faixa etária indicada. Caracteristicamente, o público mais atendido é constituído por estudantes de origem mais pobre das cidades e zonas rurais, e as modalidades oferecidas: presencial, semipresencial e a distância. A faixa etária atendida é heterogênea, porém, a presença dos jovens entre 15 e 25 anos tem sido cada vez maior, principalmente nas grandes cidades e os adultos acima de 40 anos ainda prevalecem no interior (LOPES, 2017; JAEL et al., 2017). Além disso, dentre as problemáticas enfrentadas no EJA destacam-se: a existência de cerca de $11 \mathrm{mi}$ lhões de analfabetos brasileiros; a negligência do Estado Brasileiro com a educação, uma vez que $41 \%$ de jovens e adultos não possuem o ensino fundamental completo e $52 \%$ não tem o ensino médio; e ainda uma queda de 3,5 milhões dos matriculados em 2019 (DA SILVA, ACIOLI e RAMOS, 2020).

O EJA tem as funções de reparar, garantindo uma educação de qualidade; equalizar, dando oportunidades para os que foram prejudicados no acesso e permanência na escola devido a processos de exclusão múltiplos; e por fim, qualificar, para educação contínua ao 
longo da vida. Assim, contribui para que essas pessoas adquiram habilidades e conhecimentos necessários para exercer seus direitos e controlar seus destinos, além da redução da pobreza e aumento da inclusão social no país ao possibilitar melhores oportunidades de emprego (MACHADO, 2016).

Uma das particularidades desse público é a sua bagagem de experiências e significados adquiridos ao longo da vida. Por isso, visando sua participação mais ativa, é necessário que o professor legitime e relacione a leitura de mundo que possuem com a visão científica para que sejam capazes de interpretar, investigar e refletir melhor diversos temas. Quanto a isso, a pedagogia de Paulo Freire e a teoria da aprendizagem significativa de David Ausubel podem ser apontadas como promissoras para a reflexão ligada ao EJA.

O método dialogado de Paulo Freire propõe que se perceba este estudante como dotado de saberes, valorizando sua realidade cultural. Silva (2017) reforça que é preciso aprender a ensinar de forma a articular o conteúdo com a realidade do aluno, valorizar o diálogo, respeitar os saberes dos educandos e descobrir maneiras de ensinar para formar cidadãos conscientes e atuantes na sociedade. $\mathrm{O}$ autor considera ainda que a educação deve ser definida como prática de liberdade e conscientização, em negação a memorização mecânica. 
A Teoria da Aprendizagem Significativa de David Ausubel propõe que deve-se reconhecer os conhecimentos prévios como principais contribuintes na formação dos novos conhecimentos (JAEL et al., 2017). Também reforça a importância de que esses jovens e adultos tenham tais conhecimentos valorizados, de maneira que os novos saberes sejam ancorados nos anteriores para serem assimilados de forma significativa. Para isso, as novas ideias e informações devem ser relevantes e fazer sentido para o aluno no uso cotidiano (SERBIM e DOS SANTOS, 2017).

Dentre os principais fatores que contribuem para evasão escolar estão as situações de vulnerabilidade, gravidez precoce, repetência e necessidade de trabalhar. Alguns jovens repetentes e indisciplinados relatam também sofrer com uma postura desmotivadora, em vez de acolhedora, por parte dos profissionais da educação, levando-os a não enxergar a escola como projeto para o futuro, a encarar o EJA como punição e até a desistir dos estudos (LOPES, 2017). Por outro lado, a sensação de não pertencimento no ensino regular, incentivo da família, vontade de acelerar os estudos, recuperar o tempo perdido e melhorar as condições de trabalho são fatores determinantes para a volta aos estudos na modalidade do EJA (JAEL et al., 2017).

Em geral, os estudantes julgam a disciplina de química como difícil e não relacionada ao cotidiano. No 
EJA, isso se reforça devido ao pouco tempo para estudar, longo período afastado da escola e cansaço após o dia de trabalho. Assim, é preciso refletir sobre o que deve ser ofertado na disciplina para atender as demandas da sociedade, aproximando o conteúdo a sua aplicabilidade, usando metodologias que valorizem o tratamento mais qualitativo para oportunizar uma formação de qualidade e amenizar a exclusão experimentada por eles (ALBUQUERQUE, BARROSO e BATISTA, 2017).

Em contraposição, a realidade percebida nas salas de aula é a prevalência da metodologia tradicional usando o livro didático como único recurso. O professor é o transmissor de informações e o aluno um ser desprovido de conhecimento, exercendo o papel de receptor. Muitas vezes a inadequada estrutura física da escola, a não promoção de capacitação dos profissionais e currículos extensos são empecilhos para a utilização de outros métodos de ensino, agravando a desmotivação, diminuindo a frequência e contribuindo para a evasão (JAEL et al., 2017).

Os conteúdos devem estar centrados nos conhecimentos, avanços tecnológicos e em aspectos sociais e éticos da Química para que o aluno a compreenda, interprete informações transmitidas pela mídia, avalie suas aplicações e implicações tecnológicas e seja capaz de tomar decisões. Quanto a isso, o uso de contextualização, experimentos, metodologias ativas e temas geradores 
como: preservação ambiental, alimentos, combustíveis, remédios, cosméticos, inseticidas, energia, entre outros, podem ser favoráveis a motivação, retirando os alunos da condição de passivos e da prática de memorização, tornando-os mais participativos e engajados (RIBEIRO e MELLO, 2019). Por isso, o professor deve atuar como um problematizador, criando um clima de discussão e mostrando que o aluno é capaz de pensar e formular teorias.

\section{Método do estudo de caso}

Dentre as possíveis metodologias que atendam aos princípios supracitados, temos o Estudo de Caso, que é uma variante do Aprendizado Baseado em Problemas, também conhecido por Problem Based Learning (PBL). Esse método surgiu no final da década de 60 e foi desenvolvido visando colocar os alunos em contato com problemas reais ou simulados para investigar aspectos científicos e sociais e estimular o pensamento crítico. Já foi implantado em diversos níveis de ensino e cursos pelo mundo, como medicina, administração, direito e engenharias, objetivando aproximar o estudante da sua futura área de atuação. Nele, são criadas narrativas sobre dilemas a serem analisados e resolvidos, chamadas de casos. Cada caso deve permitir identificar e definir o problema, avaliar informações necessárias, a resolução e apresentação da solução adequada. Dessa forma, o método permite atingir um ensino centrado no aluno e contextualizado, 
treinar tomada de decisão, comunicação oral e escrita, assim como o trabalho em grupo (SÁ e QUEIROZ, 2020).

Além disso, há um crescente uso dessa estratégia no ensino da área das ciências da natureza, com destaque para área de Química Ambiental devido a sua estreita relação com problemas da sociedade atual, permeando aspectos socioeconômicos e éticos. As publicações que incluem o uso deste método permitem que o professor consulte e adapte o caso pronto e o use em sua aula disseminando cada vez mais essa estratégia de ensino (SÁ e QUEIROZ, 2020).

A partir da curiosidade gerada, surge o interesse pelo estudo, levando a questionamentos e busca por soluções. Nesse processo, novas habilidades e significados são construídos, e é nessa perspectiva que o Estudo de Caso, constituído por uma situação-problema, se insere (ALVARENGA e CARMO, 2016). As recomendações para elaboração de um bom caso e gerar curiosidade são: ser útil para os estudantes, envolver situações que eles saibam enfrentar e enxerguem relevância em estudar, despertar o interesse pela questão a ser resolvida e conter questões atuais. Sua aplicação se dá nos formatos: exposição do caso; discussão e/ou; realização de atividades em pequenos grupos. Os dois últimos são os mais encontrados na literatura, já a simples exposição, encontra-se combinada aos outros formatos para promover envolvi- 
mento e não apenas transmissão de informações (SÁ e QUEIROZ, 2010).

Uma variante desse método, sob o formato de pequenos grupos, ocorre quando durante as discussões cada grupo representa o ponto de vista de um personagem envolvido no problema social analisado. Eles devem argumentar a fim de defender os interesses de tais personagens. Assim, o debate acontece em um cenário de júri, permitindo o estudo sob diferentes aspectos do tema. No fim, eles decidem em conjunto, ou por jurados definidos previamente, quais foram os melhores argumentos a fim de reunir soluções para o caso (FLÔR, 2007 apud FARIA e FREITAS-REIS, 2016a).

\section{Agrotóxicos}

As Orientações Curriculares Nacionais para o Ensino Médio indicam a discussão, sob diferentes pontos de vista, de aspectos sociocientíficos atuais, articuladamente com conteúdos químicos, pois propicia que os alunos compreendam o seu entorno e construam coletivamente respostas a problemas baseados em valores mais justos, sustentáveis e éticos (BRASIL, 2006).

Nesse sentido, a escolha dos agrotóxicos como tema gerador em diversas situações em sala de aula é adequado, pois é recorrente na mídia e permite associa- 
ção com uma vasta opção de conteúdos. Além disso, o Brasil ocupa o lugar de maior consumidor de agrotóxicos do mundo devido a sua economia ser fortemente baseada em produtos agrícolas. Agregado a esse aspecto, existem também os amplos impactos do uso desses produtos na saúde, atingindo expressivamente trabalhadores rurais, comunidades no entorno e consumidores em todo o território (SIMÕES e ALVES, 2017; RIBEIRO, PASSOS e SALGADO, 2019).

\section{Pela Lei Federal nº 7.802/89, agrotóxicos são:}

[...] produtos e agentes de processos físicos, químicos ou biológicos, destinados ao uso nos setores de produção, no armazenamento e beneficiamento de produtos agrícolas, nas pastagens, na proteção de florestas, nativas ou plantadas, e de outros ecossistemas e de ambientes urbanos, hídricos e industriais, cuja finalidade seja alterar a composição da flora ou da fauna, a fim de preservá-las da ação danosa de seres vivos considerados nocivos, bem como as substâncias e produtos empregados como desfolhantes, dessecantes, estimuladores e inibidores de crescimento (BRASIL, 1989, p. 1).

Os Parâmetros Curriculares Nacionais complementares sugerem, quanto aos agrotóxicos, que o trabalho esteja associado à competência de representação e comunicação, como a leitura e interpretação de textos científicos e de diferentes meios de comunicação 
(BRASIL, 2002). Ao discutir em grupo os efeitos dos agroquímicos na saúde e meio ambiente, os estudantes podem desenvolver habilidades de investigação, raciocínio e análise, além de conhecer a estrutura química e características de tais compostos, reunir informações sobre vantagens, desvantagens e alternativas, como agricultura orgânica e controle natural de pragas (RIBEIRO, PASSOS e SALGADO, 2019).

A conscientização em torno da temática agrotóxicos é extremamente importante pois a exposição a eles leva a intoxicações agudas e crônicas, podendo desencadear casos de câncer, doenças neurológicas, como a doença de Parkinson, hepáticas, renais, respiratórias, imunológicas e endócrinas, distúrbios psiquiátricos e alterações mutagênicas (MURAKAMI et al., 2017). Os mais atingidos são os manipuladores rurais, pois sofrem exposição direta prolongada e muitas vezes possuem baixo grau de instrução, levando a falta de conhecimento do risco que correm. Há que se citar também a negligência por parte dos proprietários das terras ao não proporcionarem equipamentos de proteção individual (EPIs) e nem treinamento aos funcionários.

Dentre os agrotóxicos mais vendidos no Brasil, temos o glifosato, 2,4-D, metamidofós, atrazina, carbendazim, paraquate e acefato. Muitos deles estão na lista de agrotóxicos altamente perigosos em outros países no mundo, porém, permitidos no Brasil. Em 2019, por 
exemplo, foram liberados mais de 239 agrotóxicos, mesmo sendo muitos desses vetados na Europa (ROCHA, 2019).

Em vista do exposto, o objetivo deste trabalho foi aplicar o método do Estudo de Caso sobre a temática agrotóxicos no ensino de química orgânica para alunos do Ensino de Jovens e Adultos, com o intuito de investigar a eficiência no processo de aprendizagem significativa e também, o grau de percepção e aceitação da metodologia pelos estudantes, visando contribuir na construção de um ensino baseado na valorização dos conhecimentos prévios, diálogo e discussão socioambiental crítica.

\section{Metodologia}

Esta pesquisa se dá como parte do projeto desenvolvido pelo grupo de pesquisa em Ensino de Química/Bioquímica da UFRRJ para dissertação do Programa de Mestrado Profissional em Química em Rede Nacional (PROFQUI) da Universidade Federal Rural do Rio de Janeiro (UFRRJ). A aplicação das atividades se deu no final do ano de 2019 em uma escola da Rede Estadual de ensino situada no município de Seropédica/RJ.

A instituição escolar e todos os participantes foram esclarecidos dos objetivos e possíveis riscos e benefí- 
cios de sua participação nesta pesquisa sendo assinado o Termo de Consentimento Livre e Esclarecido (TCLE) e Termo de Anuência autorizados pelo Comitê de Ética em Pesquisa da UFRRJ (Protocolo $\mathrm{N}^{\circ}$ 036/2020), Processo $\mathrm{N}^{\circ}$ 23083.028963/2019-19.

A escola atende ao ensino de nível médio regular, nos turnos matutino e noturno, e de Jovens e Adultos, somente no noturno. A turma participante do presente estudo pertencia ao módulo final do EJA, com carga horária de 3 h-aula de química por semana, tinha o conteúdo de Química Orgânica previsto no currículo e era composta por 40 alunos com idade acima de 18 anos, sendo que somente 29 participaram efetivamente de todas as atividades.

A pesquisa consistiu em uma sequência didática, iniciada com uma aula reservada a aplicação de questionários semi-abertos para realização de diagnóstico quanto aos conhecimentos prévios dos alunos sobre o tema. As perguntas tinham como objetivo expor a percepção dos alunos sobre agrotóxicos e em que grau eram favoráveis ao uso dos mesmos.

Na segunda aula, se deu a apresentação do tema Agrotóxicos por meio de reportagens em vídeo: "Brasil tem 40 mil casos de intoxicação por agrotóxicos em uma década" (REDAÇÃO, 2019), "Governo aprova registro de mais 51 agrotóxicos, totalizando 262 no ano” (G1, 2019) e 
"Dois lados da moeda: Agrotóxico" (DOIS, 2016) e a notícia "Anvisa reclassifica mais de 1.900 agrotóxicos e retira 600 produtos dos rótulos de maior risco" (TOOGE, 2019). A partir disso, abriu-se espaço para o diálogo e os estudantes expuseram o que conheciam sobre o tema e suas opiniões. Em seguida, a professora comentou sobre a definição de tais compostos segundo a lei, os tipos e o uso no Brasil.

Na terceira aula, usando uma apresentação de slides foram estudadas as estruturas químicas dos principais defensivos usados no Brasil, sendo comentadas características, aplicações e implicações. Conceitos como representação estrutural, condensada e molecular das cadeias carbônicas e classificações do carbono e das cadeias carbônicas foram trabalhados em sala de aula. Depois, voltou-se aos agroquímicos e analisou-se suas estruturas quanto às classificações estudadas. Foram realizadas atividades de fixação com base na construção das moléculas dos agroquímicos a partir de bolinhas de isopor pintadas de cores diferentes para cada elemento químico e palitos, com posterior construção da fórmula molecular. Foi distribuído um resumo do conteúdo em papel e um link para um formulário Google contendo três questões múltipla-escolha também para a fixação.

Na quarta aula, foi realizado um " $Q U I Z$ interativo" usando uma apresentação de slides animada com 10 perguntas de verdadeiro ou falso. Os alunos participaram 
ativamente respondendo as perguntas utilizando plaquinhas com frente contendo um $\mathrm{V}$, em verde, e verso contendo um F, em vermelho. Essa estratégia permitiu a verificação visual e qualitativa do volume de acertos e erros, permitindo comentar as questões relembrando o conteúdo. Também foi pedido que contabilizassem seus acertos para que ao final se autoavaliassem quanto ao desempenho pela escala sugerida: 1 a 3 acertos (pode melhorar); 4 a 6 (bom); 7 a 9 (muito bom) e 10 (excelente).

Em seguida, foi utilizado o recurso de slides para apresentação da dinâmica do Estudo de Caso sobre a história do personagem Carlos Mendes. Os estudantes foram divididos em grupos, cada um representou um ponto de vista sobre o caso: Trabalhadores agrícolas; Empresas do ramo agrícola; Órgão que regulamenta e fiscaliza agrotóxicos; Profissionais da área da saúde; e, Agricultura sustentável. Cada grupo recebeu uma folha para diário de pesquisa e duas semanas para preparação de argumentos para resolução do caso.

A semana seguinte foi dedicada ao auxílio e elucidação de dúvidas sobre o preparo da atividade. Na última aula, as ideias, argumentos e informações pesquisadas foram discutidas. Ao final, um questionário contendo as mesmas questões iniciais foi aplicado para finalização das atividades. Portanto, a análise do presente estudo se deu de forma qualitativa de acordo com as impressões 
sobre as dinâmicas em sala e quantitativa a partir dos questionários aplicados.

\section{Resultados e discussão}

Considerando a necessidade do tema escolhido para o Estudo de Caso ser relevante para a realidade do estudante, fazendo com que o método seja atrativo e eficiente, segue uma breve correlação do tema Agrotóxicos com o município de Seropédica-RJ, onde o estudo foi realizado. O município é caracterizado historicamente por uma produção agrícola, com cerca de $20 \%$ da população vivendo em área rural (dado de 2010) e 75,5\% dos estabelecimentos classificados como de agricultura familiar (dado de 2017), com destaque para produção de alimentos orgânicos (VIANNA, 2020). Em contrapartida, uma análise recente de Alves et al. (2020) detectou concentrações altas do agrotóxico clorpirifós no alface comercializado na cidade, organofosforado altamente tóxico, evidenciando o uso indiscriminado e falta de fiscalização. Nesse sentido, os autores apontam a necessidade de pesquisas informativas visando a conscientização quanto ao uso desses químicos para a população da região.

Sobre a Pergunta 1: "Você sabe o que são agrotóxicos? (Sim ou Não)", 19 responderam que sim (73\%). E na Pergunta 2: "Se respondeu sim, o que você entende sobre agrotóxicos?”, 15 conseguiram explicar o conceito 
de forma incompleta (52\%). Portanto, os resultados revelaram um número expressivo de respostas afirmativas corroborando com o argumento de que o público desta pesquisa está em contato com esse tema no seu cotidiano, porém, não o conhece a fundo. Após a aplicação das aulas, a avaliação sobre as mesmas perguntas mostrou que, 26 responderam que sim (90\%), sendo que 19 souberam explicar satisfatoriamente (66\%). As explicações tornaram-se mais embasadas e conectadas aos problemas de saúde acarretados pela exposição a essas substâncias. Algumas respostas foram selecionadas para ilustrar essa diferença no discurso (Quadro 1).

Esses dados dialogam com as ideias de David Ausubel ao apontar que "O fator singular mais importante que influencia a aprendizagem é o que o aprendiz já conhece; descubra-o e ensine-o de acordo.” (AUSUBEL, NOVAK e HANESIAN, 1980, p. 137) Também é possível encontrar convergência dos dados obtidos com as ideias de Paulo Freire, expressas na seguinte provocação: "Por que não estabelecer uma necessária "intimidade" entre os saberes curriculares fundamentais aos alunos e a experiência social que eles têm como indivíduos?” (FREIRE, 1996, p. 15). Nesse sentido, Freire propôs que o tema se tornasse relevante e pudesse contribuir para aprendizagem significativa. 
Quadro 1: Algumas respostas da Pergunta 2 do que os alunos entendem sobre Agrotóxicos antes e depois da aplicação das atividades.

\begin{tabular}{|l|l|}
\hline Antes das Atividades: & Depois das Atividades: \\
\hline Aluno 1: "substância & Aluno 4: "entendo que o agrotó- \\
química eu acho, muito & xico ele é utilizados (sic) para \\
usada em lavouras" & matar as bacterias das verduras e \\
Aluno 2: "é uma substân- & alimentos só que o uso abusivo \\
cia colocada na fruta, nos & pode levar a cancer (sic) na pes- \\
legumes, nos alimentos e & soa que está aplicando, temos que \\
que fazem mal à saúde"” & ter consciência" \\
Aluno 3: "são os produtos & Aluno 5: "são produtos químicos, \\
utilizados em lavouras e & físicos ou biológicos, e tem objeti- \\
etc..." & vo de proteger as lavouras de \\
& pragas" \\
& Aluno 6: "é um produto químico \\
& que são (sic) muito utilizados pe- \\
& los agricultoras (sic) nas lavou- \\
& ras, para combater as pragas " \\
\hline
\end{tabular}

Fonte: Elaborado pelos autores

Sobre a Teoria da Aprendizagem Significativa de David Ausubel, Moreira (2011) cita em seu livro que "Quanto mais um indivíduo domina significativamente um campo de conhecimentos, mais se predispõe a novas aprendizagems nesse campo ou em capos afins." (MOREIRA, 2011, p. 41) Aplicando essa teoria ao ensino de jovens e adultos pressupõe-se que ao conhecerem e terem maior vivência sobre certa temática, teriam mais disposição a aprender e mais subsunçores para a aconragem de conceitos novos contextualizados. Por isso, nos 
resultados anteriores após a aplicação das atividades, percebe-se que os seus conhecimentos prévios ganharam maiores siginificados, ficando mais ricos e refinados, o que a teoria descreve como diferenciação progressiva.

Os resultados concordaram com o de Alvarenga e Carmo (2016), que ao aplicar atividades dinâmicas e Estudo de Caso no ensino de Biologia no EJA do ensino fundamental sobre o tema Abelhas, perceberam:

\begin{abstract}
[...] uma notável diferença entre os comentários anteriormente e posteriormente ditos, sendo que anteriormente os alunos apresentaram dúvidas, alguns estavam um pouco interessados, outros desinteressados [...] mas se sentiram motivados e curiosos quanto a dinâmica [...] enxergando a real necessidade destes organismos, expressando-se em falas, bem como em melhorias na habilidade oral e escrita (ALVARENGA e CARMO, 2016, p. 10).
\end{abstract}

Durante a apresentação das reportagens mais recentes sobre os agrotóxicos, houve um diálogo sobre os temas tratados revelando o que os estudantes conheciam sobre o assunto. Assim como Simões e Alves (2017) que relataram a fala indignada de um aluno " $E$ muito veneno, assim só pode gerar problemas à saúde, compramos os produtos achando que é bom para saúde e eles podem estar contaminados, é um desrespeito", o presente trabalho também percebeu o surgimento de perguntas e indignação sobre o uso, danos à saúde, fiscalização e legislação 
sobre o tema. Questionaram principalmente sobre a mudança ocorrida justamente na semana da aula sobre a classificação dos agrotóxicos (em extremamente, altamente, moderadamente e pouco tóxico ou improvável de causar dano agudo e não classificado), e também com relação aos compostos liberados no país, porém, proibidos em outros. Comentários como: "É um absurdo, não ligam para a saúde do povo", "eu acho que nada mudou com essa nova classificação, continuam fazendo mal" e "agrotóxico então prejudica a saúde do consumidor mais porém (sic) ajuda um pouco o produtor por que se o produtor não usar o agrotóxico a produção do produtor diminuem (sic) se o produtor não conseguir produzir como que vai ter alimento para botar na mesa das pessoas" demarcam o início da percepção sobre a problemática.

Ribeiro, Passos e Salgado (2019) também aplicaram vídeo motivador, explicação, tarefas de pesquisa em grupo e debate coletivo sobre agrotóxicos e conseguiram discutir questões políticas, econômicas e sociais envolvidas, percebendo que os estudantes se sentiram motivados e desenvolveram habilidades de investigação, raciocínio e análise. Oliveira (2019) concluiu que 80\% dos alunos disseram que o vídeo contribui ativamente na melhor compreensão do conteúdo.

As respostas da Pergunta 3: "Se respondeu sim na $\mathrm{N}^{\mathrm{o}} 1$, o quanto você apoia o uso de agrotóxicos conside- 
rando uma escala de 1 a 5 , onde 1 é totalmente contra e 5 é totalmente a favor?" estão mostradas na Figura 1. A partir da análise do gráfico mostrado nessa figura, pode-se perceber que antes das atividades deste estudo os alunos não tinham uma visão clara definida sobre o apoio ou rejeição ao uso de agrotóxicos, marcado por 9 respostas no nível intermediário 3 (31\%). Porém, também se percebe como segunda maior resposta o nível 1 , ou seja, totalmente contra, demonstrando que os estudantes percebiam os agrotóxicos como ligado a algo prejudicial. Observando as respostas posteriores a pesquisa, nota-se que o número de respostas desfavoráveis ao uso de agrotóxicos nos níveis 1 e 2 aumentaram.

Outra questão que chama atenção no gráfico é a de que a resposta intermediária permanece alta, o que pode-se entender que os estudantes percebem as implicações negativas que também ocorreriam na produção de alimentos se não houvessem agrotóxicos, até porque no vídeo "Dois lados da moeda: Agrotóxico" (DOIS, 2016) e nas discussões que sucederam, foram também apontadas vantagens e desvantagens quanto ao uso. 
Figura 1: Dados das respostas da Pergunta 3 sendo relacionados número de alunos $\mathrm{x}$ a nota atribuída em uma escala crescente do apoio ao uso de agrotóxicos antes e depois das atividades.

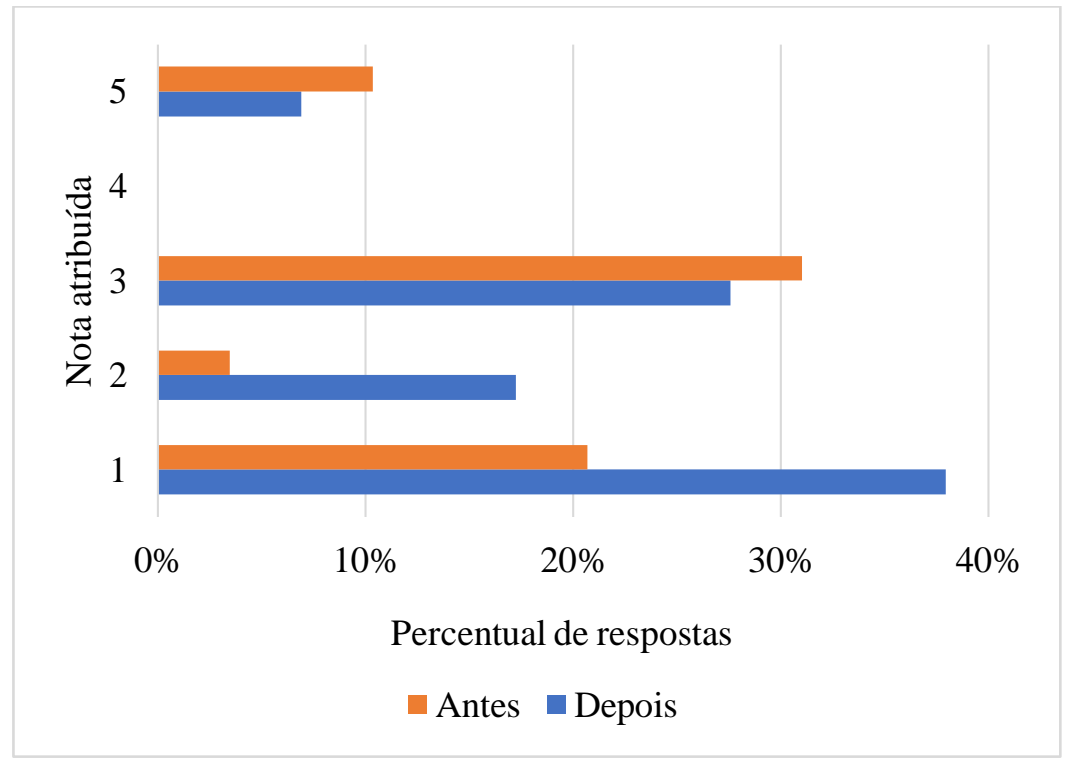

Fonte: Elaborado pelos Autores

Quanto as respostas da Pergunta 4: "Quanto a resposta anterior, justifique seu posicionamento", verifica-se que antes das atividades a maioria (18 alunos $62 \%$ ) ou não sabiam explicar a nota que atribuíram a pergunta anterior (7 alunos) ou não souberam responder deixando em branco (11 alunos). Sendo que os 11 alunos (38\%) que responderam, relataram de forma confusa e incompleta, não sustentando uma opinião clara sobre seu posicionamento. No entanto, após as atividades, notou-se 
que 17 alunos (59\%) responderam satisfatoriamente a pergunta e o restante deixou em branco.

O Quadro 2 ilustra essas percepções apresentando inclusive comparações de respostas antes e depois da mesma pessoa. As respostas também corroboraram com a conclusão anterior de que as discussões ajudaram os estudantes a perceberem os dois lados: vantagens e desvantagens do uso de agrotóxicos na produção de alimentos. Além disso, é evidente a melhora na compreensão do tema pelos alunos 4 e 7 .

Quadro 2: Algumas respostas da Pergunta 4 contendo o posicionamento dos alunos sobre Agrotóxicos antes e depois da aplicação das atividades.

\begin{tabular}{|c|c|}
\hline das atividades: & Depois das atividades: \\
\hline $\begin{array}{l}\text { Aluno 1: "acho que em } \\
\text { alguns alimentos que as } \\
\text { vezes (sic) é necessário } \\
\text { por exemplo uso para } \\
\text { eliminar fungos ou bacté- } \\
\text { rias e já em outros produ- } \\
\text { tos acho que não é neces- } \\
\text { sário o uso" } \\
\text { Aluno 4: "porque faz } \\
\text { mal" } \\
\text { Aluno 7: "na verdade não } \\
\text { lembro o que é isso" } \\
\text { Aluno 8: "bom, eu apoio, } \\
\text { porque se fizessem mal já }\end{array}$ & $\begin{array}{l}\text { Aluno 4: "agrotóxicos por um } \\
\text { lado é bom por que deixa os ali- } \\
\text { mentos bonitos e a produção é } \\
\text { mais (sic) sem ele a indústria não } \\
\text { para" } \\
\text { Aluno 7: "pois tem prejudicado a } \\
\text { saúde humana" } \\
\text { Aluno 10: "acho que um meio } \\
\text { termo, onde consiga proteger a } \\
\text { plantação, mas também não faça } \\
\text { mal a saúde!" } \\
\text { Aluno 11: "os agrotóxicos são } \\
\text { extremamente necessário (sic) } \\
\text { para a produção de alimento. }\end{array}$ \\
\hline
\end{tabular}


teriam proibido"

Aluno 9: "por ser um agente muito poluente $e$ causado (sic) de câncer alterando sabor e o valor nutricional dos produtos",

Desse (sic) que o seja utilizado adequadamente para que não seja agressivo a natureza e ao homem"

Aluno 12: "sem o uso de agrotóxicos iria ter escassez de mantimentos, porem o uso em excesso é prejudicial"

Fonte: Elaborado pelos Autores

Quanto ao estudo sobre as estruturas orgânicas e classificações, a aplicação das atividades de fixação (montagem das moléculas, exercícios pelo Google Forms e QUIZ) contribuíram para a motivação e interesse dos alunos. Como exemplo de alteração de postura destaca-se a alta adesão (100\% da turma) na realização da atividade online com uma média de acerto de 2 das 3 questões. $\mathrm{O}$ assunto que sentiram maior dificuldade foi quanto a fórmula molecular, sendo reforçado na atividade de montagem das moléculas com isopor e palitos.

Oliveira (2019) também observou a importância de se utilizar métodos avaliativos diferenciados como jogos, debates, júris e simulados em vez da simples avaliação escrita, notou que os estudantes do EJA cansados do dia de trabalho, somado a dificuldade pela defasagem e afastamento da escola por muitos anos, necessitam de aulas mais divertidas e interativas que conquiste a atenção, motive a frequência às aulas e participação. Simões e Alves (2017) também aplicaram um jogo com plaquinha 
de verdadeiro ou falso e outro de amarelinha de perguntas e observaram a contribuição para notas melhores na disciplina, com ninguém obtendo conceito insatisfatório.

A Figura 2 mostra a realização da atividade da montagem das moléculas dos Agrotóxicos mais usados no Brasil em bolinhas de isopor e palitos de dente com posterior construção da fórmula molecular. Já a Figura 2 apresenta a realização da atividade do $Q U I Z$ usando o programa PowerPoint com animações que também contou com questões relativas aos tipos de agrotóxicos: herbicida, inseticida, fungicida, bactericida, acaricida, nematicida e rodenticidas.

Figura 2: Realização da Atividade em grupo da Montagem de Moléculas de Agrotóxico: Atrazina (A), DDT (B) e Grupo de alunos do EJA durante a aula (C)
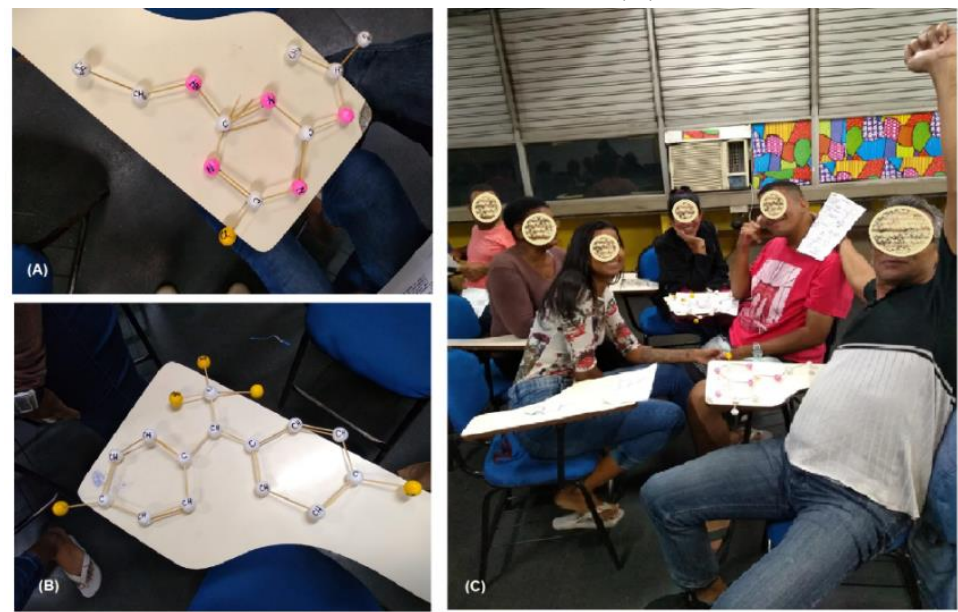

Fonte: Autores 
Figura 3: Realização da Atividade do QUIZ com as plaquinhas de Verdadeiro ou Falso levantadas

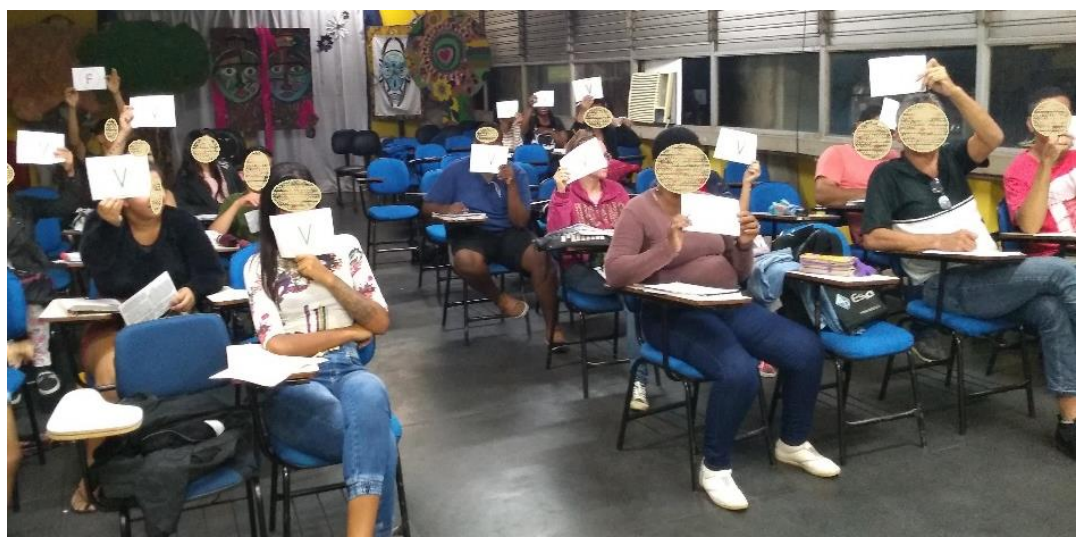

Fonte: Autores.

Sá e Queiroz (2010) ressaltam que o caso deve ser relevante, atual, curto, criando empatia pelos personagens, provocando conflito e tomada de decisão, tendo utilidade pedagógica e possibilidade de generalizações. Com base nesses critérios, o caso da "História de Carlos Mendes" foi criado pelos autores inspirado em uma história real relatada na matéria da Revista Superinteressante (GARATTONI e LACERDA, 2018) e apresentado na forma de slides também criados pelos autores que foram reunidos na Figura 4. 
Figura 4: Caso - "A história de Carlos Mendes"

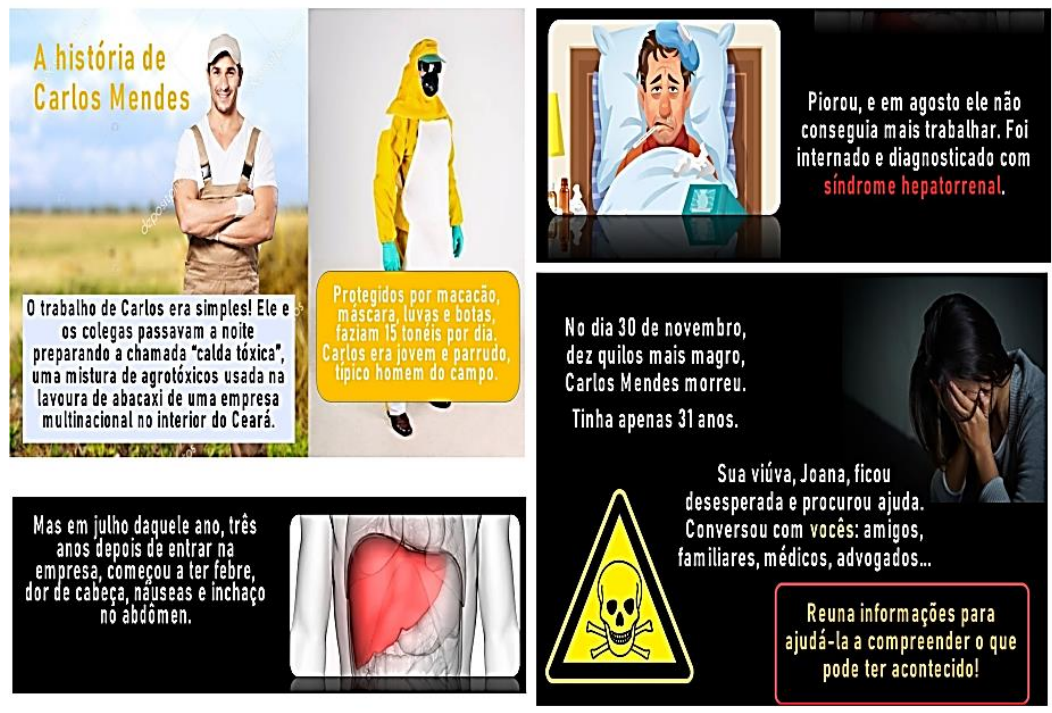

Fonte: Elaborado pelos Autores

As questões norteadoras para o Estudo de Caso foram diferenciadas para os grupos visando um olhar sobre a questão em diferentes aspectos. Tais perguntas foram preparadas para guiar e incentivar o estudante na pesquisa, interpretação e delimitação de informações úteis para a argumentação e também, para possibilitar a prática da escrita (SALES, 2017). Jones (1997 apud SÁ e QUEIROZ, 2010) aplicou um estudo parecido onde criou um tribunal de júri, no qual o problema pôde ser analisado por diversos pontos de vista (papéis): juiz, testemunha, advogados, cientistas, sociólogos, médicos, biólogos. 
As Questões norteadoras do "Diário do Caso" foram:

a) Trabalhadores agrícolas: Quem são os mais atingidos pela intoxicação por agrotóxicos? Qual a sua importância do uso de EPI's? Quais são os direitos do trabalhador em caso de doença derivada do contato com agrotóxicos?

b) Empresas do ramo agrícola: Quais são os deveres das empresas para garantir que seus trabalhadores não se contaminem por agrotóxicos? Por que existe a necessidade do uso de agrotóxicos? Cite vantagens do seu uso. Cite argumentos para defender o lado da empresa em que Carlos Mendes trabalhava. Ela promoveu medidas de proteção?

c) Órgão que regulamenta e fiscaliza agrotóxicos: Quais são os órgãos que regulamentam e os que fiscalizam o uso de agrotóxicos? Quais são as leis envolvidas no uso de agrotóxicos? Quais etapas um agrotóxico passa para ter seu uso permitido?

d) Profissionais da área da saúde: Quais são os perigos envolvidos no uso de agrotóxicos para o homem e para o meio ambiente? Quais são os principais sintomas para detectar uma intoxicação por agrotóxico? Por que são difíceis de diagnosticar? 
e) Agricultura sustentável: Quais são as alternativas para evitar o uso de agrotóxicos? Cite medidas sustentáveis agrícolas.

Assim como Silva, Vieira e Soares Jr. (2018), percebeu-se que os alunos tem dificuldade em apresentar suas respostas com uma linguagem química adequada, sendo observados erros de português e dificuldade em expressar suas respostas e opiniões. A falta de base em interpretação, escrita, oralidade e raciocínio lógicomatemático prejudica o ensino de química, principalmente no público do EJA que tem somado a isso, muitos anos afastado do ambiente escolar.

Os resultados da discussão também demonstraram que os estudantes têm dificuldade em filtrar e chegar a conclusão a partir dos vários textos disponíveis para pesquisa na internet, o mesmo é relatado por Sales (2017). Porém, revelaram uma boa argumentação e principalmente correlação com suas experiências de vida, tais como apontadas por Ausubel em sua Teoria da Aprendizagem Significativa como principal fator para assimilação de novos conhecimentos (MOREIRA, 2011). A disposição da sala em forma de "U" facilitou a participação e interação de todos e o diálogo aberto abriu espaço para o respeito dos saberes adquiridos na trajetória de vida dos alunos do EJA, conforme proposto por Paulo Freire (FREIRE, 1987). A fim de ilustrar a questão, duas contribuições que corroboram com essa conclusão estão resu- 
midas, com as palavras desses autores, e apresentadas abaixo:

Aluno 13: "O aluno relatou que admirava muito o avô, mas que estava preocupado devido ele ter perdido parcialmente a visão. Na concepção dele foi por causa do uso de agrotóxicos na pequena plantação que tem. Ele alertou que havia perigos no uso desses produtos, porém, disse que o avô não o ouvia. Despejava produto para evitar pragas e não perder seu produto sem nenhum equipamento de proteção. Por fim, relatou que o avô não possuía escolarização básica, explicando a sua relutância em entender os riscos que estava correndo levando a comorbidade citada"

Aluno 9: "Relatou que mora em uma parte bem longe do centro, tendo que andar em uma rua extensa e por fim, sem asfalto até a sua residência. Diz que no seu quintal planta algumas coisas e que uma parte estava tomada por plantas indesejadas. A partir dessa situação comprou, sem dificuldades, o produto agrotóxico herbicida chamado de "RoundUp" em uma loja na cidade. Após usar, ficou incomodado com o cheiro e se deu conta de que isso poderia lhe fazer mal. A partir da discussão em sala, esse fato veio à mente e logo conectou ao que viveu".

Locatelli, Dos Santos e Zoch (2016) também obtiveram relatos de seus estudantes, moradores de área agrícola, e perceberam que cerca de $50 \%$ já tiveram ou 
presenciaram contaminações por agrotóxicos e negligência em relação aos EPI's.

Paulo Freire aponta que "É preciso por outro lado e, sobretudo, que o educando vá assumindo o papel de sujeito da produção de sua inteligência do mundo e não apenas o de recebedor da que lhe seja transferida pelo professor." (FREIRE, 1996, p. 46) Isso foi percebido com a construção do pensamento crítico e posicionamento diante da questão ao longo do diálogo, onde a turma esteve atenta às contribuições dos colegas e também empolgada com a discussão e resolução do caso. $O$ fato apresentado pelo Aluno 9 rendeu mais diálogo, já que o produto usado possui como princípio ativo, o glifosato. Essa molécula. que havia sido muito comentada nas aulas anteriores, sendo sua molécula inclusive montada na atividade com bolinhas de isopor, por ser o mais usado no Brasil.

A seguir destaca-se uma parte dos argumentos provenientes de pesquisas na internet para discussão de cada grupo apresentados oralmente e retratados também por escrito no "Diário de Caso".

Grupo 1: "Os mais intoxicados são os trabalhadores rurais que estão expostos aos riscos, porque é um trabalho manual intenso e exaustivo com sobrecarga física $e$ mental. [...] Eles tem que ter assistencia médica e permanecer afastado do ambiente onde se lida com esse tipo de produto. Também o uso de roupa adequada como 
equipamento de EPI. [...] O caso de Lucas do Rio Verde, os moradores e animais, foram vítimas de intoxicação causada pela pulverização aérea do agrotóxico Parquat proibido em diversos paises. [...] A esposa de Carlos deve exigir que fosse (sic) investigado a fundo esse caso porque um vida se foi".

Grupo 2: "Somos nós, o consumidor (sic), os mais atingidos. Porque com o excesso de agrotóxico somos aos poucos contaminados ou seja envenenados propício (sic) a adquirir C.A. entre outras doenças [...] Equipamento de proteção individual é a maior forma de proteção do agricultor, com esse equipamento pode prevenir o trabalhador rural (sic) contra intoxicações $e$ acidentes porque (sic) podem colocar a sua vida em risco. [...] Em 2017 foram registrados 4.003 casos de intoxicação por exposição a agrotóxicos em todo o país, quase 11 por dia (...) No ano passado 164 pessoas morreram após entrar em contato com o veneno e 157 ficaram incapacitados para o trabalho, sem contar intoxicações que evoluiram para doenças crônicas como câncer [...] A esposa de Carlos Mendes deve assinalar que as indústrias químicas na área de agrotóxicos são os principais provocadores da poluição da água, do solo, do ar e dos alimentos no Brasil”.

Grupo 3: "Para obter o registro no Brasil, o agrotóxico deste passar pela avaliação de três órgãos do governo federal: MAPA, IBAMA e ANVISA. Cada um desses órgãos realiza um determinado tipo de avaliação do produto, [...] Ao MAPA é atribuída a 
responsabilidade de avaliar a eficiência $e$ o potencial de uso na Agricultura [...] Já a Anvisa avaliando o quão tóxico é o produto para a população e em quais condições o seu uso é seguro [...] Um terço dos 504 agrotóxicos que são autorizados no Brasil são proibidos na UE. Dos dez mais vendidos no Brasil atualmente dois são proibidos lá”.

Grupo 4: "Existe uma lei de 11 de julho de 1989, que dispõe sobre a pesquisa, a produção, a comercialização, a classificação de agrotóxicos, seus componentes e afins [...] Os tipos de agrotóxicos estão associados a natureza da praga que será combatida ao grupo químico à qual pertence, bem como aos danos relacionados ao meio ambiente e a saúde humana. [...] Os do Brasil (sic) tem princípios ativos proibidos em outros países o limite permite outros países respeitam o Brasil não (sic). Enquanto outros países limitam a quantidade de herbicida glifosato na água potável em o,1 miligrama por litro o Brasil permite 500 vezes mais. [...] Bem pra ele (Carlos Mendes) ter se contaminado dessa maneira provavelmente ele não estava usando as proteções que o governo fornece e nem foi ao médico assim que começaram os sintomas, se ele usou isso não tem como ser intoxicação deve ser outra coisa”.

Grupo 5: "O que os agrotóxicos podem causar ao ser humano (sic) as intoxicações crônicas aquelas que causadas suas exposição (sic) prolongada ao produtos (sic) podem gerar problemas graves, como paralisias, lesões cerebrais e hepáticas, tu- 
mores, alteração comportamentais, entre outras. [..] Agrotoxico (sic) são usados para diminuir o número de pestes que atuam em plantação e prejudicam a atividade agrrícola, mesmo que, para isso, elas causam (sic) danos irreversíveis ao meio ambiente".

Grupo 6: "porque os sintomas são muito parecido (sic) com outros tipos de doenças, como depressão, dor no estômago, coração, pressão e etc dificulta o tratamento com rapidez e identificação que é (sic) por agrotóxico [...]”.

Grupo 7: "Bactericidas: são pesticidas usados no controle de bactérias nocivas no plantio. Inseticidas: no controle de insetos. Herbicidas: no controle de ervas daninhas. Fungicidas: no controle de fungos. Acaricidas: no controle de ácaros. Entre outros. [...] efeitos são divididos em intoxicação aguda e intoxicação crônica como problemas neurológicos, motores e mentais, discursos de comportamento, problemas na produção do hormônio sexuais, infertilidade, puberdade precoce, má formação fetal, aborto, doença de Parkinson, endometriose, atrofia dos testículos e câncer de variados tipos. [...] Os agrotóxicos se esvaem pelos rios, impregnam o solo e chegam a águas subterrâneas"

Grupo 8: "A solução é utilizar o controle biológico. Essa é uma das melhores alternativas ao uso de agrotóxicos na agricultura, [...] Os biopesticidas são um tipo de pesticidas orgânicos que contém fórmulas cujos ingredientes ativos se baseiam em 
fungos e bactérias. ex. quitina, quitosano, espirosinas e feronanas de insetos e outros [...] O agrotóxico é necessário na produção de lavouras em grande escalas, mas o uso desenfreado vem seivando vidas da natureza e dos seres humanos. [...] No caso, de Carlos deveria ser criado (sic) programas para o uso adequado desses produtos. $\mathrm{Pa}$ ra que não seja protegida somente as lavouras. Deveriam visar também o controle biológico como uma alternativa para amenizar".

Para a teoria de Ausubel a captação de significados está fortemente ligada a linguagem. O estudante deve conseguir externalizar o que está aprendendo, sendo esse um processo progressivo e lento, consolidado através de resolução de situações-problema, clarificações, discriminações, diferenciações e integrações. Cita como facilitadores da aprendizagem significativa, as atividades colaborativas, presenciais ou virtuais, onde em pequenos grupos, os estudantes trocam significados e colocam o professor na posição de mediador. Enfatiza que qualquer estratégia de ensino se usada dentro de um enfoque comportamentalista do tipo certo ou errado, com a prática de cópia, memorização e reprodução leva a mera aprendizagem mecânica (MOREIRA, 2003). Portanto, a atividade proposta proporcionou esse espaço de resolução de problemas, trocas colaborativas e mediação do professor, tornando-o potencialmente significativo. 
Durante as discussões percebeu-se que os alunos ficaram presos aos detalhes das informações pesquisadas, mas ao longo do debate a conversa foi ficando mais fluida e eles participaram de forma mais crítica, espontânea e criativa. Ao fim do estudo de Caso, a turma chegou à conclusão de que medidas de fiscalização da empresa do uso de EPIs devem ser intensificadas, também que a mulher de Carlos Mendes deveria processar a empresa já que seus sintomas eram compatíveis com intoxicação por agrotóxico, mesmo ele usando proteção durante o trabalho. Devido a proximidade ser grande acreditaram que mesmo assim, seu quadro se devia a exposição a esses compostos tão tóxicos, portanto, cabendo a ela direitos a serem buscados devido a sua perda.

Através dos apontamentos feito pelos alunos, pode-se perceber que refletiram sobre diversos pontos de vista desta questão que permeia a sociedade: "Agrotóxico - sim ou não?” e conseguiram se posicionar. Portanto, em atividades deste tipo "a educação problematizadora se faz, assim, um esforço permanente através do qual os homens vão percebendo, criticamente, como estão sendo no mundo com que e em que se acham." (FREIRE, 1987, p. 46).

A reportagem que inspirou a criação do caso de Carlos Mendes, presente na matéria "O país do agrotóxico" da Revista Superinteressante, foi apresentada à turma que constatou que se tratava de um fato real, onde "sua 
viúva, processou a empresa e depois de quase uma década brigando, conseguiu um marco histórico. A Justiça deu ganho de causa, em última instância, à família- e, ao fazer isso, reconheceu Carlos Mendes que morreu por exposição a agrotóxicos" (GARATTONI e LACERDA, 2018). Os alunos se mostraram satisfeitos com a aula e muitos agradeceram e pediram por mais momentos como esse, chegando a dizer "Pena que acabou, parece que foi tão rápido. Até a próxima aula!”. De maneira geral, os resultados da literatura e do presente estudo mostram que o Estudo de Caso contribui para a aprendizagem e conexão da química com a resolução de problemas reais, sendo possível perceber maior entusiasmo e iniciativa também.

Faria e Da Silva (2012) aplicaram quatro casos distribuídos aleatoriamente por grupos de estudantes, sendo um deles com narrativa parecida com a tratada no presente estudo chamado de "Doença misteriosa em trabalhadores rurais". Assim como nesse trabalho, os estudantes concluíram que os sintomas relatados referiam-se à intoxicação por contato direto com agrotóxicos, devido ao manuseio incorreto do produto na plantação. Os resultados desse estudo mostraram que os estudantes melhoraram habilidades de trabalhar em equipe (74\%), solucionar problemas (64\%) e de argumentação (54\%). Também foram reunidos diversos dados e informações relevantes sobre o tema assim como o observado pelos grupos no caso de Carlos Mendes. 
Locatelli, Dos Santos e Zoch (2016), assim como no presente estudo, promoveram a conscientização dos estudantes de região marcadamente agrícola sobre o tema agrotóxicos, atitudes incorretas, alternativas e a conexão com a química ao tema proposto. Contudo, o fez através da análise do discurso de histórias em quadrinhos (HQ's) criadas pelos estudantes. As HQ's, como Método do Estudo do Caso, mostraram-se divertidas e estimulantes da criatividade.

Sobre o Estudo de Caso, Sales (2017) ressalta que é necessário que os professores estejam preparados para trabalhar com esse tipo de atividade, pois a resolução do caso pode conduzir a aula para destinos não previstos. Faria e Freitas-Reis (2016b) também destacam a importância de cursos de capacitação, vivência na criação, e aplicação de um caso, percebendo dificuldades e vantagens, para os profissionais se sentirem preparados a ousar e romper com a sala de aula tradicional, usualmente utilizada no EJA. Além disso, finalizam afirmando que o professor da educação básica deve participar mais efetivamente das pesquisas educacionais tornando-se professores-pesquisadores e não apenas executor das pesquisas acadêmicas. 


\section{Conclusão}

A necessidade de romper com o tradicionalismo no ensino é notória, ainda mais para o EJA, cujo público geralmente passa um dia cansativo no trabalho somado às dificuldades de aprendizado devido ao tempo decorrido fora da escola necessitando atividades que chamem atenção e gerem interesse e motivação. Esses aspectos são ainda mais agravados quando se tem em mente o aprendizado de Química, disciplina que é tida como difícil. Contudo, ainda prevalece a aprendizagem mecânica, baseada na memorização e uso de livros como único recurso didático. Este trabalho apresentou uma proposta de superação dessa problemática por meio de atividades dinâmicas e do método do Estudo de Caso, pautando-se nas teorias de Freire e Ausubel que enfatizam a valorização e respeito aos conhecimentos prévios desse público jovem e adulto para fortalecer a construção de uma aprendizagem significativa.

Com isso, os resultados mostraram uma associação entre a vivência experimentada ao longo da trajetória do aluno com o conteúdo abordado, possibilitada pelo tema Agrotóxicos, próximo a realidade dos estudantes que vivem no município Seropédica/RJ, com histórico rural. Conteúdos básicos de Química Orgânica foram tratados: fórmulas e classificação de cadeias carbônicas. A partir desse método pode-se também desenvolver habilidades requisitadas para o exercício da plena cidadania 
como fortalecimento do pensamento crítico, criativo e capacidade de resolução de problemas.

\section{Referências}

ALBUQUERQUE, B. A. de; BARROSO, M. T.; BATISTA, I. S. Características de alunos na educação de jovens e adultos: desafios ao ensino de química. Enseñanza de las ciencias: revista de investigación y experiencias didácticas, n. Extra, p. 247252, 2017.

ALVARENGA, M. M. S. C. de; CARMO, G. T. do. A construção do método estudo de caso sobre o ensino de ciências para os discentes da educação de jovens e adultos. In: III CONEDU, 3., 2016, Campina Grande. Anais [...]. Campina Grande: Realize Editora, 2016.

ALVES, D. da P. et al. Quantificação de clorpirifós em alfaces comercializadas no município de Seropédica-RJ, através de cromatografia líquida de alta eficiência. Cadernos de Agroecologia, v. 15, n. 2, 2020..

BRASIL. Lei $n^{0}$ 7.802, de 11 de julho de 1989. Dispõe sobre a pesquisa, a experimentação, a produção de agrotóxicos, seus componentes e afins, e dá outras providências. Brasília, DF, 1989.

Disponível

em: <http://www.planalto.gov.br/ccivil_03/leis/l7802.htm>. Acesso em: 2 nov. 2020.

. Lei $n^{\circ}$ 9.394, de 20 de dezembro de 1996. Estabelece Diretrizes e Bases da Educação Nacional. Brasília, DF, 1996. Disponível em: <http://www.planalto.gov.br/ccivil_o3/leis/L9394.htm>. Acesso em: 2 nov. 2020. 
. Ministério da Educação, Secretaria de Educação Média e Tecnológica (Semtec). PCN + Ensino Médio: orientações complementares - Ciências da natureza, matemática e suas tecnologias. Brasília, DF, 2002. Disponível em: <http://portal.mec.gov.br/seb/arquivos/pdf/CienciasNaturez a.pdf $>$. Acesso em: 2 nov. 2020.

. Ministério da Educação, Secretaria de Educação Básica. Orientações curriculares para o ensino médio - volume 2: Ciências da natureza, matemática e suas tecnologias. Brasília, DF, 2006. Disponível em: < http://portal.mec.gov.br/seb/arquivos/pdf/book_volume_02 _internet.pdf $>$. Acesso em: 2 nov. 2020.

DA SILVA, S.; ACIOLI, J. G.; RAMOS, M. J. B. Educação de jovens e adultos; entre lutas e descontinuidades. Brazilian Journal of Development, Curitiba, v. 6, n. 6, p. 40107-40118, jun. 2020.

AUSUBEL, D. P.; NOVAK, J. D.; HANESIAN, H. Psicologia educacional. Tradução Eva Nick. Rio de Janeiro: Interamericana, 1980.

DOIS lados da moeda: Agrotóxico. [s. l, s. n], 2016, 1 vídeo (31 min). Publicado pelo Canal Joven Pan News. Disponível em: $<$ https://www.youtube.com/watch?v=SKEW7XoSMf8>. Acesso em: 2 nov. 2020.

FARIA, F. L. de; DA SILVA, A. de F. A. Estudo de Casos e o desenvolvimento de habilidades cognitivas pelos alunos do Ensino Médio. In: ENCONTRO NACIONAL DE ENSINO DE QUÍMICA, 16, 2012; ENCONTRO DE EDUCAÇÃO DE QUÍMICA DA BAHIA, 10, 2012. Anais [...] Salvador, 2012. 
FARIA, F. L. de; FREITAS-REIS, I. A percepção de professores e alunos do ensino médio sobre a atividade estudo de caso. Ciência \& Educação, v. 22, n. 2, p. 319-333, 2016a.

. Uma proposta de divulgação da estratégia de ensino estudo de caso para professores de química do ensino médio. Revista Eletrônica Debates em Educação Científica e Tecnológica, v. 6, n. 6, p. 119-144, set. 2016b.

FREIRE, P. Pedagogia do Oprimido, $17^{\mathrm{a}}$ Ed., Rio de Janeiro: Paz e Terra, 1987.

FREIRE, P. Pedagogia da Autonomia, $25^{\text {a }}$ Ed., Rio de Janeiro: Paz e Terra, 1996.

G1. Governo aprova registro de mais 51 agrotóxicos, totalizando 262 no ano. Publicado no Site G1, 2019, 1 vídeo (3 min). Disponível em: <https://g1.globo.com/economia/agronegocios/noticia/2019/ 07/22/governo-aprova-registro-de-mais-51-agrotoxicostotalizando-262-no-ano.ghtml>. Acesso em 2 nov. 2020.

GARATTONI, B.; LACERDA, R. O país do Agrotóxico. Resista SuperInteressante, 2018. Disponível em: <https://super.abril.com.br/especiais/brasil-o-pais-doagrotoxico/>.Acesso em: 2 nov. 2020.

JAEL, R. R. P. et al. As dificuldades no processo ensinoaprendizagem de jovens e adultos. Anais do Seminário Científico do UNIFACIG, n. 3, 2018.

LOCATELLI, A.; DOS SANTOS, K. de F.; ZOCH, A. N. Unidade de Ensino Potencialmente Significativa para o ensino de química orgânica, abordando a temática dos agrotóxicos. Revista Amazônica de Ensino de Ciências, v. 9, n. 18, p. 158-172, jan/jun, 2016. 
LOPES, B. S. da S. A nova cara da EJA: O aumento de matrículas de adolescentes e jovens na modalidade de ensino de jovens e adultos. 2017. 55f. Monografia (Licenciatura em Pedagogia) - Universidade Federal do Rio de Janeiro (UFRJ), Rio de Janeiro, 2017.

MACHADO, M. M. A educação de jovens e adultos - Após 20 anos da Lei $\mathrm{n}^{\circ}$ 9.394, de 1996. Revista Retratos da Escola, Brasília, v. 10, n. 19, p. 429-451, jul./dez. 2016.

MOREIRA, M. A. Aprendizagem significativa e linguagem. In: IV ENCONTRO INTERNACIONAL SOBRE APRENDIZAGEM SIGNIFICATIVA, 4., p. 1-17, 2003, Maragogi. Conferência de Encerramento. Maragogi, 2003.

MOREIRA, M. A. Aprendizagem Significativa: a teoria e textos complementares. São Paulo: Livraria da Física, 2011.

MURAKAMI, Y. et al. Intoxicação crônica por agrotóxicos em fumicultores. Saúde Debate, Rio de Janeiro, v. 41, n. 113, p. 563-576, abr/jun 2017.

OLIVEIRA, E. I. dos S. Metodologias ativas aplicadas ao ensino de jovens e adultos. 2019. $78 \mathrm{f}$. Monografia (Licenciatura em Química) - Centro de Formação de Professores, Universidade Federal de Campina Grande, Cajazeiras-PB, 2019.

REDAÇÃO, Globo Rural. Brasil tem 40 mil casos de intoxicação por agrotóxicos em uma década. Publicado pela Revista Globo Rural, 2019, 1 vídeo (11 min). Disponível em: $<$ https://revistagloborural.globo.com/Noticias/Videos/noticia /2019/04/brasil-tem-40-mil-casos-de-intoxicacao-poragrotoxicos-em-uma-decada.html>. Acesso em 2 nov. 2020. 
RIBEIRO, D. das C. de A.; PASSOS, C. G.; SALGADO, T. D. M. A metodologia da Resolução de Problemas: uma proposta interdisciplinar sobre agrotóxicos na Educação de Jovens e Adultos. Revista Linas, v. 20, n. 43, p. 205-233, mai/ago 2019.

RIBEIRO, M. T. D.; MELLO, I. C. O ensino de química e sua relação na instrução de jovens da Educação de Jovens e Adultos. Revista da Rede Amazônica de Educação em Ciências e Matemática - REAMEC, Cuiabá - MT, v. 7, n. 2, jul/dez 2019.

ROCHA, N. Ti. Agrotóxicos: um estudo sobre os impactos no trabalho e na vida de trabalhadores rurais. 2019. 104f. Trabalho de Conclusão de Curso (Bacharelado em Serviço Social), Universidade Federal de Santa Catarina, Florianópolis, 2019.

SÁ, L. P.; QUEIROZ, S. L. Estudos de casos no ensino de química. Campinas: Editora Átomo, 2010.

SALES, E. S. "A doença de Milena": o estudo de caso como metodologia de ensino de química. 2017. 39f. Trabalho de Conclusão de Curso (Licenciatura em Química), Instituto de Química, Universidade Federal do Rio Grande do Sul, Porto Alegre, 2017.

SERBIM, F. B. do N.; DOS SANTOS, A. C. O ensino de química no PROEJA e a aprendizagem significativa: um diálogo teórico e epistemológico. In: $10^{\circ}$ ENCONTRO INTERNACIONAL DE FORMAÇÃO DE PROFESSORES, 10., 2017, Recife. Anais [...]. Sergipe: Anais do $10^{\circ}$ ENFOPE - UNIT, 2017.

SILVA, V. R. de J. Educação de Jovens e Adultos - Paulo Freire: Implicações Pedagógicas. Claraboia, Jacarezinho/PR, v. 8, p. 64-74, jul/dez 2017. 
SILVA, A. J. A. da; VIEIRA, A. A.; SOARES JR, A. L. Atividades experimentais de química no ensino da EJA. Experiências em Ensino de Ciências, v. 13, n. 4, p. 49-63, 2018.

SIMÕES, N. T.; ALVES, E. F. Utilizando a temática agrotóxico no ensino de química orgânica com alunos da educação de Jovens e Adultos. In: $37^{\circ}$ ENCOTNRO DE DEBATES SOBRE O ENSINO DE QUÍMICA - FURG, 37., nov. 2017, Carreiros. Anais [...]. Carreiros: FURG, 2017.

TOOGE, R. Anvisa reclassifica mais de 1.900 agrotóxicos e retira 600 produtos dos rótulos de maior risco, G1, São Paulo, 2019.

Disponível em: <https://g1.globo.com/economia/agronegocios/noticia/2019/ 08/02/anvisa-reclassifica-mais-de-1900-agrotoxicos-e-tira600-produtos-dos-rotulos-de-maior-risco.ghtml>. Acesso em: 2 nov. 2020.

VIANNA, M. de A. As transformações no espaço rural no município de Seropédica-RJ nas últimas décadas. Espaço e Economia, Ano IX, n. 19, 2020. 